\title{
The Mexican amber anole,Anolis electrum, within a phylogenetic context: implications for the origins of Caribbean anoles
}

\section{Citation}

Del Rosario Castañeda, María, Emma Sherratt, and Jonathan B. Losos. 2014. “The Mexican Amber anole,Anolis Electrum, Within a Phylogenetic Context: Implications for the Origins of Caribbean Anoles." Zoological Journal of the Linnean Society 172 (1) (August 4): 133-144. doi:10.1111/zoj.12159.

\section{Published Version}

doi:10.1111/zoj.12159

\section{Permanent link}

http://nrs.harvard.edu/urn-3:HUL.InstRepos:34309457

\section{Terms of Use}

This article was downloaded from Harvard University's DASH repository, and is made available under the terms and conditions applicable to Open Access Policy Articles, as set forth at http:// nrs.harvard.edu/urn-3:HUL.InstRepos:dash.current.terms-of-use\#OAP

\section{Share Your Story}

The Harvard community has made this article openly available.

Please share how this access benefits you. Submit a story.

Accessibility 
Title: The Mexican amber anole, Anolis electrum, within a phylogenetic context: implications for Caribbean anoles origins

María del Rosario Castañeda ${ }^{1}$, Emma Sherratt $^{1}$, and Jonathan B. $\operatorname{Losos}^{1}$

${ }^{1}$ Department of Organismic and Evolutionary Biology and Museum of Comparative Zoology, Harvard University, 26 Oxford Street, Cambridge, MA 02138, USA

Corresponding author: María del Rosario Castañeda

Department of Organismic and Evolutionary Biology and Museum of Comparative Zoology, Harvard University, 26 Oxford Street, Cambridge, MA 02138, USA

Phone: (1) 617-496-9099

Fax: (1) 617-495-5667

Email: mcastanedaprada@fas.harvard.edu

Running title: Anolis electrum, the Mexican amber lizard 


\begin{abstract}
Anoles are well known examples of adaptive radiation and convergent evolution. Their phylogenetic relationships have been intensely studied, but their fossil record remains fairly poor, limiting understanding of their evolutionary history. We present new data on Anolis electrum, the first discovered fossil anole and sole vertebrate described from Mexican amber, using x-ray Computed Tomography. We inferred the phylogenetic relationships of $A$. electrum and comment on its use in estimating the age of Anolis origins, which has significant relevance in explaining the presence of anoles on Caribbean islands. Anolis electrum is represented by two pieces of amber containing parts of the same individual. Partial squamation and skeleton details are well preserved, though only ten characters commonly used in phylogenetic analyses could be scored. The lack of informative characters resulted in A. electrum being inferred in 14 different places within four recognized subclades: Dactyloa, cristatellus series, darlingtoni series, and Norops, one of which corresponds to previously suggested close relationships. Results fail to support a suggested age estimation of 130 Myr for Anolis; consequently, the hypothesis of overwater dispersal as the explanation for the occurrence of anoles on Caribbean islands remains the most robust hypothesis.
\end{abstract}

Keywords: Anolis electrum, Mexican amber, phylogenetics, x-ray computed tomography. 


\section{INTRODUCTION}

With close to 400 species currently recognised and extensive morphological, ecological and behavioural diversity, Anolis lizards have become a textbook example of adaptive radiation and convergent evolution. Although significant progress has been achieved in the reconstruction of their phylogenetic relationships (Jackman et al., 1999; Nicholson, 2002; Poe, 2004; Castañeda \& de Queiroz, 2013), understanding of the evolutionary history of Anolis is constrained by the small number of fossils available. Indeed, other than very recent late Pleistocene/Holocene fossils (Etheridge, 1965, 1966; Steadman, Pregill \& Olson, 1984; Roughgarden \& Pacala, 1989; Chun, 2007), the published fossil record is limited to four specimens preserved in amber (Lazell Jr., 1965; Rieppel, 1980; de Queiroz, Chu \& Losos, 1998; Polcyn et al., 2002). Three of these are from early-to-middle Miocene deposits in the Dominican Republic (Iturralde-Vinent \& MacPhee, 1996; Iturralde-Vinent, 2001), all of which appear to be members of the chlorocyanus clade (or species group) extant on Hispaniola today (de Queiroz et al., 1998; Polcyn et al., 2002).

The fourth amber fossil, and the first described, comes from the mines around Simojovel, Chiapas, where most Mexican amber originates (Poinar Jr. \& Brown, 2002; Solórzano Kraemer, 2007). The age of Mexican amber is still under debate. It is well accepted that Simojovel deposits occur in three lithostratigraphic units, La Quinta Formation, the Mazantic shale and the Balumtun sandstone, but disagreement lingers on whether these formations are late Oligocene to early Miocene in age (22.5-26 Myr; Langenheim, 1966;

Poinar Jr., 1992; Poinar Jr. \& Brown, 2002), or as young as early to mid-Miocene (15-20 Myr) and probably contemporaneous with the Dominican amber (Solórzano Kraemer, 
2007, 2010). The Mexican anole fossil was described as Anolis electrum by Lazell in 1965 (Lazell Jr., 1965). In those pre-cladistic days, Lazell (1965) suggested several possible close relationships for A. electrum based on overall morphological similarity to extant taxa and biogeography. After examining a series of potential candidate species, Lazell (1965) determined that four species most closely agreed with the combination of characters found in A. electrum: A. chloris, A. fuscoauratus, A. limifrons and A. maculiventris. Ultimately, he concluded that $A$. electrum most likely was closely related to $A$. limifrons because it is the most morphologically similar species known to occur in the same area today. Although interest in anole evolution, phylogeny, and biogeography has thrived since then, A. electrum has not been re-examined nor included in explicit phylogenetic analyses. This is somewhat surprising given that, in theory, A. electrum could provide important insights into controversies over Central American anole biogeography (Nicholson, 2005) as well as issues concerning anole evolutionary history (Pinto et al., 2008; Schaad \& Poe, 2010).

After 47 years of obscurity for Anolis electrum, the need of a re-evaluation of its phylogenetic position emerged from Nicholson et al.'s (2012) controversial revision of anole history. Based on an analysis of phylogenetic data, Nicholson et al. (2012) proposed that anoles originated $130 \mathrm{Myr}$ and that extant taxa began to diverge $95 \mathrm{Myr}$. This estimate is substantially older than both recent estimates based on DNA data that place the stem age of the Anolis clade at 23-75 Myr (Mulcahy et al., 2012), 53-72 Myr (Townsend et al., 2011), or 81-83 Myr (Mulcahy et al., 2012; Pyron \& Burbrink, 2013), as well as previous estimates based on albumin divergence and early molecular clock methods, which place the diversification of extant taxa (crown clade age) at 40 and 66 Myr, respectively (Shochat \& 
Dessauer, 1981; reviewed in Losos, 2009). Nicholson et al.'s (2012) much older date of Anolis divergence is significant because it supports the hypothesis that the presence of anoles on Caribbean islands is the result of vicariance rather than overwater dispersal, a scenario that is incompatible with the younger dates for anole divergence. Examination of Nicholson et al.'s (2012) dating analysis indicates that their proposed older date is mainly due to the position of A. electrum used for fossil calibration (the other calibration point, based on Dominican fossils, is considered in the Discussion) and to a lesser extent its assigned age. Following Lazell (1965), Nicholson et al. (2012) placed A. electrum as sister taxon to the recently diverged clade of A. limifrons and A. zeus (the latter taxon being recently split off from the former based on differences in scalation and male dewlap coloration; Köhler \& McCranie, 2001). They also dated the divergence between A. electrum and A. limifrons $+A$. zeus at 28 Myr based on an age estimate of Mexican amber that is older-and potentially much older—than current estimates (Langenheim, 1966; Poinar Jr., 1992; Langenheim, 2003; Solórzano Kraemer, 2007, 2010). The combination of the phylogenetic placement of A. electrum and the assigned age of Mexican amber resulted in Nicholson et al. (2012) arriving at a very ancient age for anole origins. Given this surprising conclusion, we decided to re-examine A. electrum to attempt to determine its phylogenetic position. We provide new data on this important and little-known specimen using modern tools not available to Lazell (1965) a half-century ago. We further use topology tests to explicitly evaluate the relationship between A. electrum and its potential close relatives proposed by Lazell (1965; i.e., A. chloris, A. fuscoauratus, A. limifrons and A. maculiventris).

\section{MATERIALS AND METHODS}




\section{Data collection}

Anolis electrum is composed of two amber pieces (holotype: UCMP 68496, paratype: UCMP 68497) assumed to contain posterior and anterior portions of the same individual, respectively. The reported type locality is Simojovel, Chiapas, though more precise information is not available (Lazell Jr., 1965). External morphology was examined using a dissecting microscope. Photographs of the fossils were taken using a digital camera (JVC KY-F7SU 3 chip Digital CCD Microscopy Camera) attached to a dissecting microscope (Leica MZ125 with a $0.5 x$ lens), linked to a computer with the software Auto-Montage (Synoptics, Ltd.). Auto-Montage integrates a series of images taken at different focal planes to produce an image with extended depth of field. For further examination, we used High-Resolution X-ray Computed Tomography (HRXCT), which uses a series of radiographs to build a 3D representation of the specimen. The two fossils were scanned using a Nikon (Metris) X-Tek HMXST 225 machine housed at Harvard University's Centre for Nanoscale Systems. Both specimens were scanned with a molybdenum target, $55 \mathrm{kV}, 200 \mu \mathrm{A}, 1000 \mathrm{~ms}$ exposure, $0.1^{\circ}$ rotation step, and no filter. The reconstructed voxel size of UCMP 68496 is $0.010 \mathrm{~mm}$ and UCMP 68497 is $0.014 \mathrm{~mm}$. HRXCT scans of each specimen are stored as a series (stack) of TIFF images at Harvard University Museum of Comparative Zoology; raw CT slice data available on request, reconstructed images available on Morphobank (O'Leary \& Kaufman, 2012; http://morphobank.org/permalink/?P1108). Post-processing of the scan data was done using VGStudio MAX v2.2 (Volume Graphics, 2001). The different elements in the fossil (e.g. bone, amber, air) are represented in each slice by voxels of different grey values, white being the most dense (i.e., bone) and black the least dense (i.e., air). The slices were segmented by applying a threshold (using the half-maximum height protocol; Spoor, 
Zonneveld \& Macho, 1993) to retain white voxels to represent bone, and black voxels to represent air-filled voids. When stacked, the thresholded slices produce a volumetric representation of the specimen, which we used for anatomical inspection. HRXCT allows the fossils to be more thoroughly examined, and with greater resolution than was previously possible.

\section{Phylogenetic analyses}

We scored as many morphological characters as possible following Poe's (2004) character descriptions. These data were combined with a dataset comprised of morphological (Poe, 2004), and molecular data (mitochondrial genes ND2, 5 transfer-RNAs [tRNA ${ }^{\text {Trp }}$, tRNA ${ }^{\text {Ala, }}$, tRNA ${ }^{\text {Asn }}$, tRNA ${ }^{\text {Cys }}$, tRNA $\left.{ }^{\text {Tyr }}\right]$, and the origin for light-strand replication $\left[\mathrm{O}_{\mathrm{L}}\right]$; Macey et al., 1997; Jackman et al., 1999; Creer et al., 2001; Jackman et al., 2002; Glor et al., 2003;

Harmon et al., 2003; Schulte II, Valladares \& Larson, 2003; Nicholson et al., 2005;

Nicholson, Mijares-Urrutia \& Larson, 2006; Castiglia et al., 2010; Castañeda \& de Queiroz, 2011). The complete data matrix is available in Morphobank (http://morphobank.org/permalink/?P1108). Although other molecular markers are available for anoles (e.g., nuclear RAG1, mitochondrial $c y t-b$ ), we focused on the ND2 gene and five adjacent tRNAs, because this mitochondrial region is the one with the broadest taxonomic coverage in anoles, which prevented unnecessary missing data added to the dataset. DNA sequences were aligned using Clustal X (Thompson et al., 1997) under default settings, and translated into amino acids using MacClade v.4.07 (Maddison \& Maddison, 2001) to confirm the correct translation frame. Sequences coding tRNAs were aligned manually, following Kumazawa and Nishida's (1993) model of tRNA secondary structure. 
The resulting matrix included 91 morphological characters and 1474 DNA bases for 182 taxa, including seven non-Anolis outgroup species.

The phylogenetic relationships of Anolis electrum were estimated in PAUP* v. 4.0b10 (Swofford, 2002) using parsimony methods. We used equal costs for state transformations, except for multistate ordered morphological characters, which were weighted such that the range of each character equals 1 . A heuristic search with 2000 replicates of random stepwise addition was performed, with all other settings left as default. Nodal support was assessed using non-parametric bootstrap resampling (Felsenstein, 1985) using 100 bootstrap pseudoreplicates and heuristic searches with 50 replicates of random stepwise addition (other settings left as default) for each bootstrap replicate.

\section{Hypothesis testing}

We used topology tests to explicitly evaluate if the hypotheses of Anolis electrum as sister taxon to A. chloris (Dactyloa clade), A. fuscoauratus, A. limifrons or A. maculiventris (Norops clade) are supported by the data. We performed four parsimony analyses (using the same settings as above), each incorporating one of the alternative hypotheses of sister relationship with A. electrum as a topological constraint. Each constrained topology was constructed using MacClade (Maddison \& Maddison, 2001), and imported into PAUP* as a topological constraint. To test if each resulting optimal tree of the constrained analysis was significantly different from the optimal tree of the unconstrained analysis, we performed Wilcoxon signed-rank tests (Templeton, 1983) as two-tailed tests in PAUP*. 


\section{RESULTS}

\section{Morphology of Anolis electrum}

During the fossilisation process of amber, organic material fully surrounded by the resin is preserved with remarkable detail. For vertebrate inclusions, the soft tissue, although apparently visible through the translucent amber, has actually rotted away, leaving an airfilled void lined by an impression of the skin. The skeletal elements are often preserved (particularly the limbs); they can remain in place, or may become disarticulated and free to move around inside the void. In both specimens, the lizard is surrounded by a reddish halo caused by mineralisation of the soft tissue that occurs when the amber is fractured and the organic matter comes into contact with air. From the HRXCT scans, we found the mineralised skin has a similar X-ray attenuation to the bone, obscuring the natural margin between the two materials. The HRXCT scans also revealed that there are few skeletal elements preserved in the holotype and paratype specimens, but the outline of the air-filled voids retain remarkable details of the soft tissue (Figs. 1-2; Supplementary material S1, S2, videos 1-2). Considering the anatomical parts preserved in each specimen, and the dimensions of the limbs in each, we agree with Lazell's (1965) conclusion that these are two halves of the same animal. The following specimen descriptions are based primarily on CT scan reconstructions and serve as a complement to the detailed scale information provided by Lazell (1965).

Holotype (UCMP 68496, Fig. 1, S1). This specimen includes the right hindlimb, a left hindtoe, and a portion of the body. The ventral aspect of the hindlimb and posterior portion of the body lie against the underside of the amber block (Fig. 1B, S1). The only skeletal 
elements preserved in this piece are the parts of the forefeet. The hindlimb and abdomen are hollow, air-filled voids in the amber, the edges of which preserve great detail of the scales. The only part of the left foot that is preserved is most likely the fourth hindtoe, lying adjacent to the right lower leg; the most distal phalanx is preserved as skeleton, and there is an air-filled void surrounding the skin of the expanded toepad, outlining approximately two thirds of the hindtoe. Phalanges and metatarsi of the right hindfoot are preserved in full and unbroken. An air-filled void outlines the right limb, specifically the hindtoes, foot, lower leg and most of the thigh (rendered green in Fig. 1A), and stops at the proximal end of the thigh. Skin of the upper thigh or groin has mineralised where the amber is fractured (rendered white in Fig. 1A). Scales on the ventral side of the abdomen are visible, imprinted on the amber, with a yolk sac scar positioned medially. There are 8 scales in $1 \mathrm{~mm}$, measured along the yolk sac scar. The skin in the most anterior and most posterior areas of the abdomen has also mineralised. No skeletal elements are preserved in this region.

Reconstructing air-filled voids in the amber from the HRXCT data revealed details of an invertebrate inclusion. The specimen, an ant of the family Formicidae, genus Azteca (C. Moreau, pers. comm), is very well preserved lying adjacent to the right hindfoot (Fig. 1C). The total length of the body is $3.6 \mathrm{~mm}$, width of the head $0.8 \mathrm{~mm}$, and length of one antenna $1.9 \mathrm{~mm}$. Lazell (1965) did not remark on this inclusion.

Paratype (UCMP 68497, Fig. 2, S2). This specimen includes the anterior portion of the body, and the preserved skeletal elements are restricted to the forelimbs and the skull. The forelimbs and dewlap are visible through both sides of the amber block (Fig. S2). Despite 
this, Lazell (1965) indicated the absence of a throat fan. Skeletal elements preserved are mainly of the forelimbs. Of the right forelimb, the humerus is preserved, but the proximal end is not well-defined. The ulna and radius are preserved, although they are not perfectly aligned with each other. The metacarpals and phalanges of all five foretoes are also preserved. The wrist appears to be broken so that the bones are not continuous as in life but slightly separated. The ends of the limb bones appear to be square-ended, indicating the epiphyses have not yet fused and thus that the specimen is a juvenile. Of the left forelimb, only the phalanges and metacarpals are preserved. An air-filled void in the amber outlines the upper and lower parts of the forelimb, showing details of the scales. The proximal end of the left forelimb shows mineralisation of the skin where it meets the torso.

The trunk, neck and head are preserved as an air-filled void that is open to the edge of the amber piece. The trunk is broken where the ribcage (not preserved) would be. The skin of these body parts has mineralised around the periphery of the void. The head is partially preserved. Figure 2B shows the head from ventral view in which most of the skull has broken away at the edge of the amber piece. The head appears to have been severed at an angle across the rostrum, removing the left side of the head, and the right side from the middle of the mouth forward. The right side of the skull is preserved in part (Fig. 2C): the lateral margins of the parietal are preserved, adjacent to the postorbital bone and posterolateral part of the frontal bone. Mineralised soft tissue obscures the lateral portion of the skull, but the quadrate is visible. The squamosal may be preserved but if so, it is obscured by the mineralised tissue. The surangular is preserved and continuous with the dentary bone. Only the posterior half of the dentary is preserved. The coronoid process is 
visible behind the jugal. The jugal is almost completely preserved; a portion is missing at the boundary between the jugal and postorbital bar. The maxilla is articulated with the jugal and lies anterior to the dentary as in life, up to the edge of the amber. Only the posterior half of the maxilla is preserved. Four maxillary teeth and four or five dentary teeth are preserved, all tricuspid. The right half of the palate, the right pterygoid and ectopterygoid are preserved in place. The presence of pterygoid teeth could not be confirmed given the amount of mineralization in the surrounding tissue.

From the HRXCT renderings of the fossils, we update the morphometric and meristic data provided by Lazell (1965); his measurements in parentheses when available): the thigh is $5.5 \mathrm{~mm}(5.2 \mathrm{~mm})$ and the lower leg is $4.5 \mathrm{~mm}(4.1 \mathrm{~mm})$, measured from the insertion of the limb on the body wall to the knee joint, and from this point to the point of inflexion on the heel, respectively. The distance from the heel to the base of hindtoe IV is $3.2 \mathrm{~mm}$, and from the base to the tip is $4.4 \mathrm{~mm}$, giving a total of $7.7 \mathrm{~mm}(7.0 \mathrm{~mm})$. The toepad of right hindtoe IV is $0.5 \mathrm{~mm}(0.9 \mathrm{~mm})$ at the widest part. We count between $17-20(21-22)$ lamellae under the third and fourth phalanges of right hindtoe IV, depending on the landmark used for counting (lamellae are counted from the most distal end of the third phalanx to the most proximal end of the fourth phalanx; the latter landmark usually identified by bending the hindtoe). In addition, the preserved section of the torso is $3.2 \mathrm{~mm}$ wide and $6.2 \mathrm{~mm}$ long. From the estimated thigh length, we estimate the snout-vent length of $A$. electrum to be 24 mm, based on juvenile and adult data of A. brevirostris, A. coelestinus, and A. cybotes (T. Sanger, unpublished data), using the equation $\operatorname{logSVL}=\log$ Thigh $/ 1.01-0.65$. Given the range of hindlimb variation in these three species, the SVL of the specimen could range 
between $20-28 \mathrm{~mm}$. The left upper arm is $3.1 \mathrm{~mm}$, measured from the limb insertion to the elbow joint, and the right humerus is $3.0 \mathrm{~mm}(3.9 \mathrm{~mm})$, although this is an underestimate as the most proximal end (the epiphysis and a small amount of the diaphysis) is missing. The left forearm is $3.6 \mathrm{~mm}(3.2 \mathrm{~mm})$, measured from the elbow to the wrist, and the right ulna and radius are each $2.2 \mathrm{~mm}$. The left forefoot is $3.5 \mathrm{~mm}$ from the wrist to the tip of foretoe IV (3.6 $\mathrm{mm})$. The preserved limb bones are only represented by the diaphyses; the epiphyses are not preserved, therefore the limb lengths reported are underestimates of the total bone length. The section of lower jaw preserved (from the posteriormost point on the surangular to the anteriormost point on the broken dentary) is $4.3 \mathrm{~mm}$ long, and the preserved section of maxilla is $1.7 \mathrm{~mm}$. The height of the head at the parietal is c. $2.7 \mathrm{~mm}$. Lazell (1965) measured $4.8 \mathrm{~mm}$ for the head "at the level of the interparietal", but there is no reliable boundary of the back of the skull preserved and visible on the HRXCT scan.

\section{Phylogenetic analyses}

Ten of the 91 morphological characters described in Poe (2004) were scored for Anolis electrum. In agreement with Lazell (1965), we scored the following characters: digital pad of the 'raised' type (i.e., toepads overlap second phalanx or 'alpha-type', as opposed to toepads non-overlapping the second phalanx or 'beta-type'), absence of enlarged middorsal scales (as opposed to presence of middorsal scales larger than surrounding scales), ventral scales arranged in transverse rows (i.e., each ventral scale is bordered posteriorly by two scales, as opposed to arranged in diagonal rows, in which each ventral scale is bordered posteriorly by three scales), interparietal scale bordered posteriorly by small scales gradually transitioning into dorsal granules (as opposed to midnuchal scales in rows of 
bulbous scales distinct from dorsal scales), dorsal and ventral scales smooth (as opposed to keeled), and supradigital scales keeled (as opposed to smooth). Additionally, we scored: 1) the preoccipital scale absent (as opposed to present), 2) the fold of skin over the dorsal rim of the ear opening absent (as opposed to present), 3) the interparietal scale separated from the supraorbital semicircles by one or more rows of scales (as opposed to in contact with supraorbital semicircles), 4) the posteroventral corner of the jugal convex (as opposed to concave), and 5) the coronoid labial process present (as opposed to absent). The dewlap is extended completely and is attached posteriorly to the level of the arm insertion. The imprint left by the skin on the amber reveals that scales covering the dewlap are scattered throughout the skin, as opposed to organized in rows (Fig. 2A, Fig S2F).

Köhler (2014) recently compiled a list of characters useful in taxonomic descriptions. Several of these (condition of terminal phalanx, number of rows of enlarged dorsal scales, condition of supradigital, ventral, and dorsal scales, number of scales between supraorbital semicircles and interparietal scale, size of scales adjacent to interparietal scale) are included in our phylogenetic analysis. Three other characters can be scored in Anolis electrum, but were not included in the phylogenetic reconstruction because comparable data are not available for many species. These characters are: 1) Diameter of parietal scale: Longitudinal $=0.95 \mathrm{~mm}$, transverse $=0.48 \mathrm{~mm}$ 2) Subdigital pad width (IV toe) forefoot= $0.58 \mathrm{~mm}$, hindfoot $=0.51 \mathrm{~mm}$; and 3) Condition of parietal depression: Deep. Researchers interested in using these traits should bear in mind that the A. electrum specimen is a juvenile, and thus data may not be comparable to that obtained from adults of extant species. 
One hundred bases corresponding to sections of the tRNAs and the $\mathrm{O}_{\mathrm{L}}$ were excluded from the analyses due to ambiguous alignment. The resulting matrix includes $1374 \mathrm{bp}, 91$ morphological characters, and 182 taxa, 41 of which are missing molecular data. The parsimony analysis yielded 14 fully resolved most parsimonious trees of 224233.85 steps $(\mathrm{CI}=0.089, \mathrm{RI}=0.517)$, which only differ in the position of A. electrum. All major subclades of Anolis (as shown in previous phylogenetic analyses; Jackman et al., 1999; Nicholson, 2002; Castañeda \& de Queiroz, 2013) are inferred, except the sagrei series within the Norops clade, which was inferred to be paraphyletic. Anolis electrum is placed in 14 alternative positions (Fig. 3B-E): 6 within the Dactyloa clade (Fig. 3B), sister to $A$. darlingtoni (Fig. 3C), 5 within the cristatellus series (Fig. 3D), and 2 within the Norops clade (Fig. 3E). A list of synapomorphies supporting the alternative sister relationships of $A$. electrum is provided in Supplementary Material S3. The maximum agreement subtree (or common pruned tree; Finden \& Gordon, 1985), which results from excluding the same set of taxa from the primary trees (in this case A. electrum), is shown in Figure 3A.

\section{Hypothesis testing}

Only one of the previously suggested close relationships of A. electrum (that with A. chloris) was inferred in the 14 most parsimonious trees (Fig. 3B). Even though none of the other three proposed relatives of $A$. electrum (i.e., A. fuscoauratus, A. limifrons or A. maculiventris) were inferred in any of most parsimonious trees, the WSR tests failed to find statistical differences between the unconstrained optimal trees and those inferred using the topological constraints $(P=0.648,0.857,0.317$, respectively). 


\section{DISCUSSION}

After many years since its description, we re-examined Anolis electrum using HRXCT, a novel technology not available to Lazell (1965) that allowed reconstruction of the specimens in three-dimensions and visualisation of more morphological details. We corroborate his findings that the holotype and paratype specimens most likely belong to the same individual. The type specimen (UCMP 68496; Fig. 1, 1S) includes the complete right hindlimb, a portion of the abdomen, and a detached portion of the left hindfoot. As noted by Lazell (1965), the egg-sac scar on the abdomen is noteworthy, in that it identifies the specimen as a newly hatched lizard. The paratype specimen (UCMP 68497; Fig. 2, 2S) includes a portion of the head and trunk and both forelimbs, one of them with complete skeletal elements. The specimens show well-preserved expanded toepads, and scalation details on the limbs and the ventral aspect of the trunk. The skin appears not to have decayed prior to fossilisation, unlike the Dominican amber anoles, which show substantial decay (Rieppel, 1980; de Queiroz et al., 1998; Polcyn et al., 2002). The HRXCT scans revealed that the shape of the jugal in A. electrum is convex and the coronoid labial process is present. They also revealed well-preserved bone elements in the right hindfoot, the right forefoot and the entire left forelimb. The HRXCT data further allowed an update of Lazell's (1965) measurements and provided a better appreciation of the amount of detail preserved in this unique fossil (see supplementary material videos).

Possessing laterally expanded subdigital toepads and an extensible dewlap, Anolis electrum is clearly an anole. By re-examining the only known specimen and scoring additional 
morphological characters, we hoped to place A. electrum within anole phylogeny, potentially shedding important insights on the evolution of this diverse and well-studied clade. Unfortunately, because the fossil is broken and incomplete, it could only be scored for a few of the morphological characters commonly used in phylogenetic analyses of anoles. Informative systematic characters like the condition of the caudal vertebrae and the pectoral girdle are missing. This lack of data derives not only from the incompleteness of the preserved skeleton, but also because of mineralisation of the preserved soft tissue, which obscures phylogenetically informative bone sutures, processes and rugosities.

As a result of the lack of phylogenetically informative characters, all that we can conclude is that A. electrum is an anole. Our analyses produced many equally parsimonious trees, all of which only differ in the placement of A. electrum. Amongst these trees, A. electrum is variously placed in four different subclades that span the full breadth of anole phylogeny, from the Dactyloa clade that diverges from all other anoles at the base of the tree to the Norops clade nested deep within it (Fig. 3A). These ambiguous placements indicate that nothing conclusive can be said about A. electrum's position. Notably, however, one place in which A. electrum is not inferred is near A. limifrons or two of the three alternative close relationships suggested by Lazell (1965; i.e., A. electrum close to either $A$. fuscoauratus or $A$. maculiventris). Although topology tests failed to reject any of these close relationships, the amount of missing data in A. electrum (99\%) can make these or any other alternative hypothesis involving the position of A. electrum almost impossible to reject. Hence, no support was found for Lazell's (1965) conclusion that A. electrum and A. limifrons are closely related, the hypothesis accepted by Nicholson et al. (2012). This should not come as 
a surprise. Not only was Lazell's (1965) work based on overall morphological similarity, as was common at that time, but the characters on which he based his reasoning-meristic and qualitative aspects of scalation-have been shown to exhibit high levels of convergence and parallelism thus providing little information for phylogenetic relationships (Castañeda \& de Queiroz, 2013).

If A. electrum were truly the sister taxon of a recent clade, as suggested by Nicholson et al., (2012), then Anolis would be very old, indeed. Conversely, a position deep in anole phylogeny would only indicate a minimal age between 15-26 Myr for Anolis (Langenheim, 1966; Poinar Jr., 1992; Solórzano Kraemer, 2007, 2010). This, indeed, is the case for the other three amber anoles, which appear to be members of the chlorocyanus clade from Hispaniola (de Queiroz et al., 1998; Polcyn et al., 2002). This clade branches off early in anole phylogeny, and hence these fossils only reveal that the crown age of Anolis is older than 15-20 Myr, the estimated age of Dominican amber (Iturralde-Vinent \& MacPhee, 1996; Iturralde-Vinent, 2001). The phylogenetic uncertainty of A. electrum means in reality that it cannot inform understanding of the timing of anole evolution. Other than demonstrating that Anolis evolved between 15-26 Myr, which was already known from the existence of contemporaneous amber specimens from the Dominican Republic, A. electrum does not constrain the timing of anole diversification. However, based on the clear uncertain phylogenetic position of $A$. electrum and the lack of positive evidence supporting the close relationship between A. electrum and A. limifrons, we can conclude that the age estimation of Anolis provided by Nicholson et al. (2012) is unfounded. Moreover, although the fossils currently available for Anolis are uninformative regarding the age of the entire clade, 
molecular-based dating studies have come to broadly concordant conclusions about the timing of the anole radiation (Townsend et al., 2011; Mulcahy et al., 2012). These studies agree that the age of Anolis is somewhere in the range of 40-70 millions years (crown clade). Under this scenario and given the geological history of the Caribbean (reviewed in Nicholson et al., 2012) such an age is too young to permit a vicariant explanation for the occurrence of anoles on the islands of the Greater Antilles. Rather, in the light of the evidence currently available, the hypothesis of overwater dispersal accounting for their occurrence on these islands today remains as the most robust hypothesis.

Dating issues aside, the lack of phylogenetic certainty about A. electrum is disappointing for another reason. This fossil could have provided significant information concerning the perplexing biogeographic pattern present in anoles of mainland Central and South America. Mainland anoles form two different clades, Dactyloa and Norops. The older Dactyloa not only is less species rich than the much younger mainland Norops clade (83 species vs. 150), but it also has a much smaller geographic distribution. Dactyloa occurs over the northern half of South America, but extends into Central America only as far north as northern Costa Rica. By contrast, Norops is found throughout Dactyloa's range, but continues north well into Mexico. Explaining this unexpected pattern has proven difficult; it is still unclear if Dactyloa used to occur farther north but has been supplanted by Norops, or if the distribution of Dactyloa has been historically restricted to its current geographic range. Establishing whether A. electrum was a member of the Dactyloa or Norops clades-mainly distinguished by differences in the caudal vertebrae, a character missing in the specimencould have helped decide between these two alternative scenarios. 
Since Lazell's (1965) description of Anolis electrum, we have learned that Mexican amber is the fossilized resin of the leguminous Hymenaea sp. tree, which is secreted from the trunk and the roots (Poinar Jr., 1992). Because of its place of secretion, and because resin generally entraps invertebrate species that are active on tree trunks and the forest floor (Henwood, 1993; Penney, 2002; Poinar Jr., 2010), we can posit that $A$. electrum was a tropical forest dwelling species, active on tree trunks or around the base of the tree. Moreover, the Mexican amber forest may have been located near a mangrove forest, as evidenced by fossil plants and invertebrate fauna inclusions that are related to extant species now found in coastal zones and mangroves (Langenheim, 1966, 1967; Poinar Jr., 1992; 2003; Solórzano Kraemer, 2007, 2010). One of those inclusions is present in the type specimen (UCMP 68496), though previously not described by Lazell (1965), a wellpreserved ant of the family Formicidae. The position of the ant in this fossil, very close to the hindfoot, suggests the ant was caught in the amber after an attempt to feed on the dead lizard, and thus reveals an intriguing insight into the biological interaction of fauna in this ancient world.

As part of the increasing scientific interest in Mexican amber (e.g., Poinar Jr. \& Brown, 2002; Solórzano Kraemer, 2007; Edgecombe et al., 2012; Durán-Ruiz et al., 2013), three new Mexican anole fossils have emerged from obscurity, one of which is currently being described (Martínez-Grimaldo et al., 2013). In general, vertebrates in Mexican amber, compared with a diverse array of invertebrates (Solórzano Kraemer, 2007, 2010), are extremely rare, making A. electrum an invaluable piece of evidence of the presence of 
anoles in Central America during the Miocene and now more so in light of the new findings. We can only hope the new discoveries of the anole fauna from Mexican amber will help clarify the outstanding questions.

\section{ACKNOWLEDGEMENTS}

The CT scans were performed in part at the Center for Nanoscale Systems (CNS), a member of the National Nanotechnology Infrastructure Network (NNIN), which is supported by the National Science Foundation under NSF award no. ECS-0335765. CNS is part of Harvard University. We thank David M. Fite Fund for financial support, Patricia Holroyd and the University of California Museum of Paleontology for lending the specimens, Corrie Moreau for help in identifying the ant, Thomas Sanger and Natalie Jacewicz for access to unpublished data, Francisco Riquelme for providing comments on an earlier version, and the National Science Foundation (DEB-0918975) for support.

\section{REFERENCES}

Castañeda MdR, de Queiroz K. 2011. Phylogenetic relationships of the Dactyloa clade of Anolis lizards based on nuclear and mitochondrial DNA sequence data. Molecular Phylogenetics and Evolution 61: 784-800.

Castañeda MdR, de Queiroz K. 2013. Phylogeny of the Dactyloa clade of Anolis lizards: New insights from combining morphological and molecular data. Bulletin of the Museum of Comparative Zoology 160: 345-398.

Castiglia R, Annesi F, Bezerra AMR, García A, Flores-Villela 0. 2010. Cytotaxonomy and DNA taxonomy of lizards (Squamata, Sauria) from a tropical dry forest in the 
Chamela-Cuixmala Biosphere Reserve on the coast of Jalisco, Mexico. Zootaxa 2508: $1-29$.

Chun WCH. 2007. An anole lizard preserved in Colombian copal. Herpetological Review 38: 294-296.

Creer DA, de Queiroz K, Jackman TR, Losos JB, Larson A. 2001. Systematics of the Anolis roquet series of the southern Lesser Antilles. Journal of Herpetology 35: 428-441.

de Queiroz K, Chu L, Losos JB. 1998. A second Anolis lizard in Dominican amber and the systematics and ecological morphology of Dominican amber anoles. American Museum Novitates 3249: 1-23.

Durán-Ruiz C, Riquelme F, Coutiño-José M, Carbot-Chanona G, Castaño-Meneses G, Ramos-Arias M. 2013. Ants from the Miocene Totolapa amber (Chiapas, Mexico), with the first record of the genus Forelius (Hymenoptera, Formicidae). Canadian Journal of Earth Sciences 50: 495-502.

Edgecombe GD, Vahtera V, Stock SR, Kallonen A, Xiao X, Rack A, Giribet G. 2012. A scolopocryptopid centipede (Chilopoda: Scolopendromorpha) from Mexican amber: synchrotron microtomography and phylogenetic placement using a combined morphological and molecular data set. Zoological Journal of the Linnean Society 166: 768-786.

Etheridge R. 1965. Fossil lizards from the Dominican Republic. Quarterly Journal of the Florida Academy of Sciences 28: 1-24.

Etheridge R. 1966. Pleistocene lizards from New Providence. Quarterly Journal of the Florida Academy of Sciences 28: 349-358. 
Felsenstein J. 1985. Confidence limits on phylogenies: An approach using the bootstrap. Evolution 39: 783-791.

Finden CR, Gordon AD. 1985. Obtaining common pruned trees. Journal of Classification 2: 255-276.

Glor RE, Kolbe JJ, Powell R, Larson A, Losos JB. 2003. Phylogenetic analysis of ecological and morphological diversification in Hispaniolan trunk-ground anoles (Anolis cybotes group). Evolution 57: 2383-2397.

Harmon LJ, Schulte II JA, Larson A, Losos JB. 2003. Tempo and mode of evolutionary radiation in iguanian lizards. Science 301: 961-964.

Henwood AA. 1993. Ecology and taphonomy of Dominican Republic amber and its inclusions. Lethaia 26: 237-245.

Iturralde-Vinent MA. 2001. Geology of the amber-bearing deposits of the Greater Antilles. Caribbean Journal of Science 17: 141-167.

Iturralde-Vinent MA, MacPhee RDE. 1996. Age and paleogeographical origin of Dominican amber. Science 273: 1850-1852.

Jackman TR, Irschick DJ, De Queiroz K, Losos JB, Larson A. 2002. Molecular phylogenetic perspective on evolution of lizards of the Anolis grahami series. Journal of Experimental Zoology B 294: 1-16.

Jackman TR, Larson A, de Queiroz K, Losos JB. 1999. Phylogenetic relationships and tempo of early diversification in Anolis lizards. Systematic Biology 48: 254-285.

Köhler G, McCranie JR. 2001. Two new species of anoles from northern Honduras (Squamata: Polychrotidae). Senckenbergiana Biologica 81: 235-245. 
Köhler, G. 2014. Characters of external morphology used in Anolis taxonomy—Definition of terms, advice on usage, and illustrated examples. Zootaxa 3774: 201-257.

Kumazawa Y, Nishida M. 1993. Sequence evolution of mitochondrial tRNA genes and deep-branch animal phylogenetics. Journal of Molecular Evolution 37: 380-398.

Langenheim JH. 1966. Botanical source of amber from Chiapas. Ciencia 24: 201-211.

Langenheim JH. 1967. Preliminary investigations of Hymenaea courbaril as resin producer. Journal of the Arnold Arboretum 48: 203-230.

Langenheim JH. 2003. Plant Resins. Chemistry, Evolution, Ecology, and Etnobotany. Timber Press: Portland, Oregon, USA.

Lazell Jr. JD. 1965. An Anolis (Sauria, Iguanidae) in amber. Journal of Paleontology 39: 379382.

Losos JB. 2009. Lizards in an evolutionary tree: Ecology and adaptive radiation of anoles. University of California Press: Berkeley.

Macey JR, Larson A, Ananjeva NB, Papenfuss TJ. 1997. Evolutionary shifts in three major structural features of the mitochondrial genome among Iguanian lizards. Journal of Molecular Evolution 44: 660-674.

Maddison DR, Maddison WP. 2001. MacClade: Analysis of phylogeny and character evolution. Version 4.07. Sunderland, Massachusetts, USA: Sinauer Associates.

\author{
Martínez-Grimaldo RE, Riquelme F, Martínez-Méndez N, Luna B, Zuñiga L, Alvarado- \\ Ortega J, Losos JB, Castañeda MdR. 2013. Anole lizards (Squamata: Dactyloidae) \\ from the Miocene Chiapas amber, with comments on broader aspects of anoles \\ evolution. In: Reynoso VH, Oseguera-Montiel B and Flores-Mejía P, eds. VIII \\ Congreso Latinoamericano de Paleontología \& XIII Congreso Mexicano de
}


Paleontología. Guanajuato, México: Sociedad Mexicana de Paleontología, A. C. Museo Dugès, Universidad de Guanajuato.

\section{Mulcahy DG, Noonan BP, Moss T, Townsend TM, Reeder TW, Sites Jr. JW, Wiens JJ.}

2012. Estimating divergence dates and evaluating dating methods using phylogenomic and mitochondrial data in squamate reptiles. Molecular Phylogenetics and Evolution 65: 974-991.

Nicholson KE. 2002. Phylogenetic analysis and a test of the current infrageneric classification of Norops (beta Anolis). Herpetological Monographs 16: 93-120.

Nicholson KE. 2005. Historical biogeographic relationships within the tropical lizard genus Norops. In: Donnelly MA, Crother BI, Guyer C, Wake MH and White ME, eds. Ecology and Evolution in the Tropics: A Herpetological Perspective. Chicago, IL: The University of Chicago Press.

Nicholson KE, Crother BI, Guyer C, Savage JM. 2012. It is time for a new classification of anoles (Squamata: Dactyloidae). Zootaxa 3477: 1-108.

Nicholson KE, Glor RE, Kolbe JJ, Larson A, Hedges SB, Losos JB. 2005. Mainland colonization by island lizards. Journal of Biogeography 32: 929-938.

Nicholson KE, Mijares-Urrutia A, Larson A. 2006. Molecular phylogenetics of the Anolis onca series: A case history in retrograde evolution revisited. Journal of Experimental Zoology B 306: 450-459.

O'Leary MA, Kaufman SG. 2012. MorphoBank 3.0: Web application for morphological phylogenetics and taxonomy. http://www.morphobank.org. 
Penney D. 2002. Paleoecology of Dominican amber preservation: Spider (Araneae) inclusions demonstrate a bias for active, trunk-dwelling faunas. Paleobiology 28: 389-398.

Pinto G, Mahler DL, Harmon LJ, Losos JB. 2008. Testing the island effect in adaptive radiation: Rates and patterns of morphological diversification in Caribbean and mainland Anolis lizards. Proceedings of the Royal Society B: Biological Sciences 275: 2749-2757.

Poe S. 2004. Phylogeny of anoles. Herpetological Monographs 18: 37-89.

Poinar Jr. G. 2010. Palaeoecological perspectives in Dominican amber. Annales de la Société Entomologique de France 46: 23-52.

Poinar Jr. G, Brown AE. 2002. Hymenaea mexicana sp. nov. (Leguminosae: Caesalpinioideae) from Mexican amber indicates Old World connections. Botanical Journal of the Linnean Society 139: 125-132.

Poinar Jr. GO. 1992. Life in Amber. Standford University Press: Standford, California.

Polcyn MJ, Rogers II JV, Kobayashi Y, Jacobs LL. 2002. Computed tomography of an Anolis lizard in Dominican amber: Systematic, taphonomic, biogeographic, and evolutionary implications. Palaeontologia Electronica 5: 1-13.

Pyron RA, Burbrink FT. 2013. Early origin of viviparity and multiple reversions to oviparity in squamate reptiles. Ecology Letters 2013. doi: 10.1111/ele.12168.

Rieppel 0. 1980. Green anole in Dominican amber. Nature 286: 486-487.

Roughgarden J, Pacala S. 1989. Taxon cycle among Anolis lizard populations: Review of evidence. In: Otte D and Endler J, eds. Speciation and Its Consequences. Sunderland, MA: Sinauer Associates. 403-432. 
Schaad EW, Poe S. 2010. Patterns of ecomorphological convergence among mainland and island Anolis lizards. Biological Journal of the Linnean Society 101: 852-859.

Schulte II JA, Valladares JP, Larson A. 2003. Phylogenetic relationships within Iguanidae inferred using molecular and morphological data and a phylogenetic taxonomy of Iguanian lizards. Herpetologica 59: 399-419.

Shochat D, Dessauer HC. 1981. Comparative study of albumins of Anolis lizards of the Caribbean islands. Comparative Biochemistry and Physiology 68A: 67-73.

Solórzano Kraemer MM. 2007. Systematic, palaeoecology, and palaeobiogeography of the insect fauna from Mexican amber. Palaeontographica Abteilung. A 282: 1-133.

Solórzano Kraemer MM. 2010. Mexican Amber. In: Penney D, ed. Biodiversity of Fossils in Amber from the Major World Deposits. Manchester, United Kindom: Siri Scientific Press. 42-56.

Spoor CF, Zonneveld FW, Macho GA. 1993. Linear measurements of cortical bone and dental enamel by computed tomography: Applications and problems. American Journal of Physical Anthropology 91: 469-484.

Steadman DW, Pregill GK, Olson SL. 1984. Fossil vertebrates from Antigua, Lesser Antilles: Evidence for late holocene human-caused extictions in the West Indies. Proceedings of the National Academy of Sciences U S A 81: 4448-4451.

Swofford DL. 2002. PAUP*. Phylogenetic Analysis Using Parsimony (* and other methods). Version 4.0b10. Sunderland, Massachusetts, USA. Sinauer Associates.

Templeton AR. 1983. Phylogenetic inference from restriction endonuclease cleavage site maps with particular reference to the evolution of humans and apes. Evolution 37: 221-244. 
Thompson JD, Gibson TJ, Piewniak F, Jeanmougin F, Higgins DG. 1997. The CLUSTAL_X windows interface: Flexible strategies for multiple sequence alignment aided by quality analysis tools. Nucleic Acids Research 25: 4876-4882.

Townsend TM, Mulcahy DG, Noonan BP, Sites Jr. JW, Kuczynski CA, Wiens JJ, Reeder TW. 2011. Phylogeny of iguanian lizards inferred from 29 nuclear loci, and a comparison of concatenated and species-tree approaches for an ancient, rapid radiation. Molecular Phylogenetics and Evolution 61: 363-380.

Volume Graphics. 2001. VGStudio MAX version 2.0. Volume Graphics GmbH, Germany. 


\section{FIGURE LEGENDS}

Figure 1. The hindlimb and abdomen of A. electrum (UCMP 68496) as revealed by HRXCT (A, C, D), and light microscopy (B). The specimen mainly comprises an air-filled void in the amber that outlines the right hindlimb, left hindtoe IV, and part of the abdomen. (A) Skeleton and air-filled voids, in ventral view, are rendered opaque: the skeleton and mineralised skin are false coloured white, the skin green, and an ant also preserved as an air-filled void is false-coloured brown. A yolk sac scar is clearly visible on the ventral side of the abdomen. The isolated left hindtoe IV lies on the ventral surface of the limb. (B) The limb and abdomen are clearly visible through the amber. (C) Close up of the ventral view of the right foot and ant, showing details of the toepad lamellae. (D) Close up of the dorsolateral view of the right hindfoot (excluding the ant) and the isolated left hindtoe IV, showing details of the limb and supradigital scales.

Figure 2. The head, forelimbs and partial body of A. electrum (UCMP 68497) as revealed by light microscopy (A) and HRXCT (B, C). (B) The head and body comprises few skeletal elements obscured by mineralised soft tissue. An air-filled void surrounding the left forelimb reveals scale details from midway along the humerus to the digits. In the right forelimb, the humerus, ulna, radius, metacarpals and phalanges of all five foretoes are preserved. (C) The skull dissected from the mineralised soft tissue shown in right lateral (left) and dorsal (right) views. For illustration purposes the skull is false coloured by bone or bone complexes in which sutures are not visible: frontal and postorbital (green), jugal and maxilla (red), pterygoid and ectopterygoid (purple), dentary, coronoid, and surangular (blue), parietal (yellow) and quadrate (turquoise). Abbreviations: $\mathrm{cr}$ - coronoid, d - 
dentary, ect - ectopterygoid, f - frontal, hu- humerus, j - jugal, mx - maxilla, par - parietal, pto - postorbital bar, ptr - pterygoid, q - quadrate, ra- radius, su - surangular, ul - ulna.

Figure 3. (A) Parsimony maximum agreement subtree showing the phylogenetic relationships of the major Anolis subclades. Bootstrap support (BS) values are shown above the branches; missing values indicate $\mathrm{BS}=0 \%$. Clades in which Anolis electrum was inferred in the 14 most parsimonious trees are indicated in color. The size of the triangles is proportional to the number of sampled taxa in each clade. (B-E) Alternative inferred positions of A. electrum within the (B) Dactyloa clade, (C) darlingtoni series, (D) cristatellus series, and (E) Norops clade. Coloured branches indicate the different inferred positions of A. electrum (the number of such alternatives is shown in parentheses below each clade). The dotted line indicates the maximum agreement placement of $A$. electrum within each clade. 


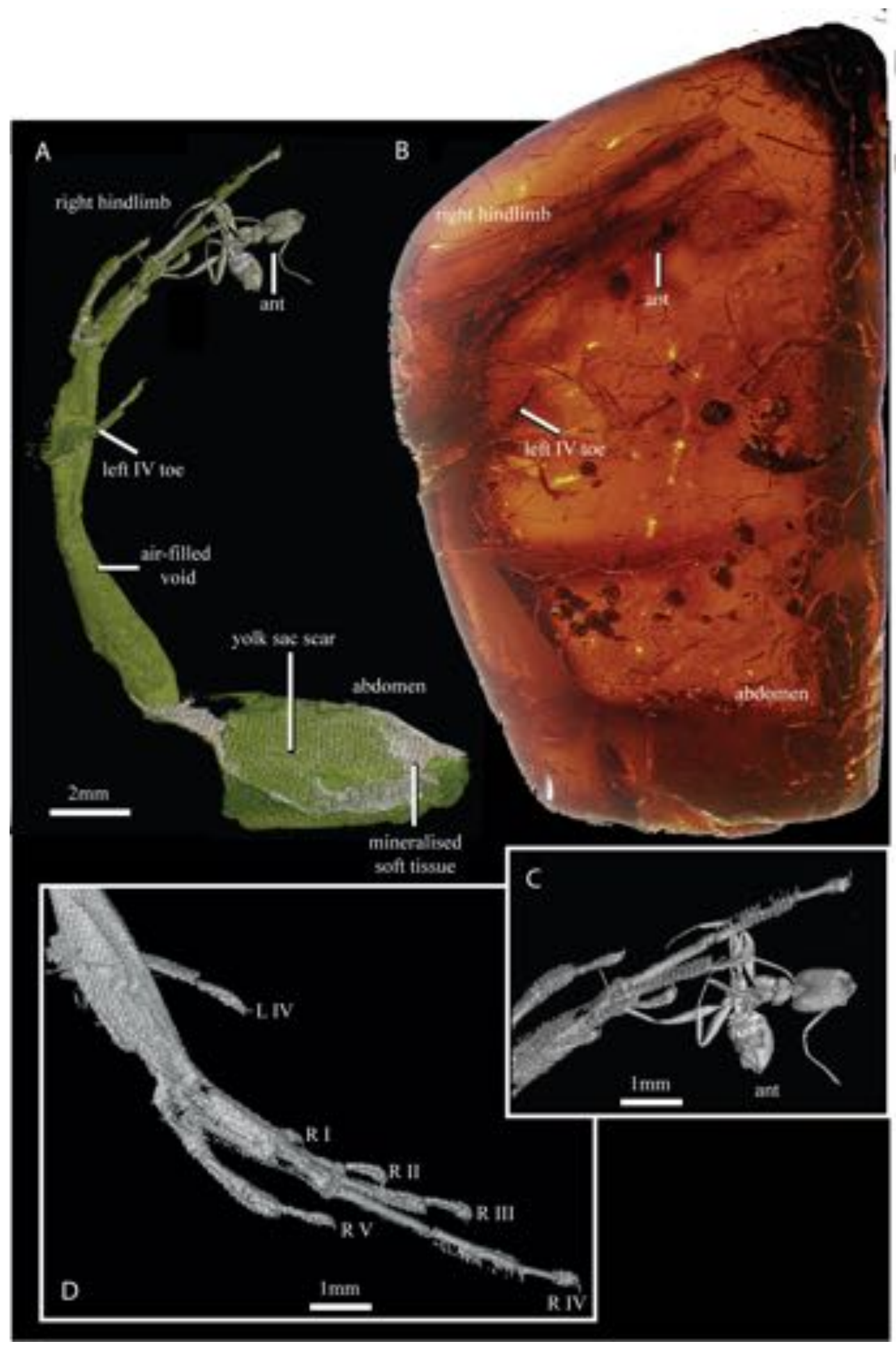

Figure 1. 


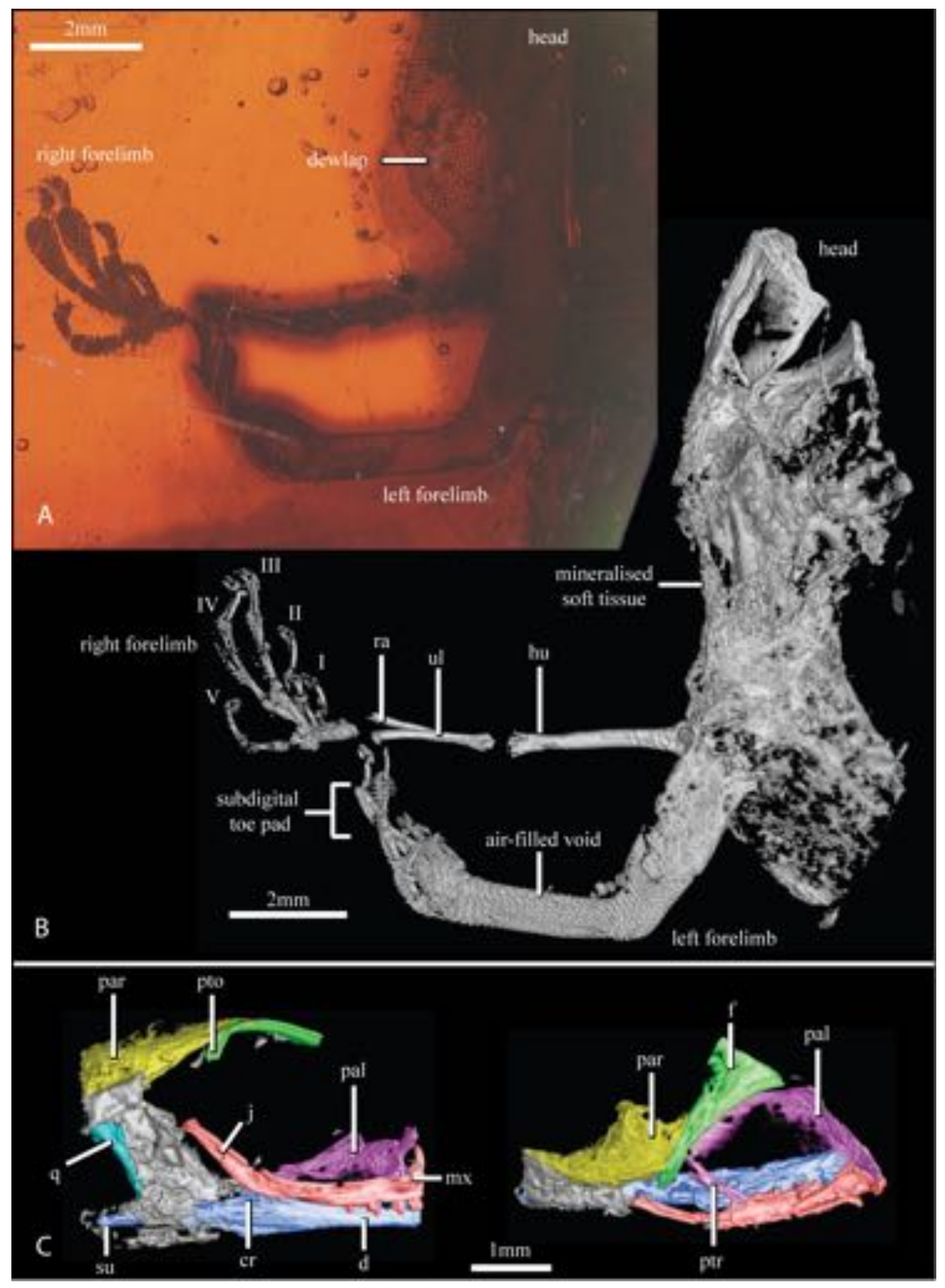

Figure 2. 


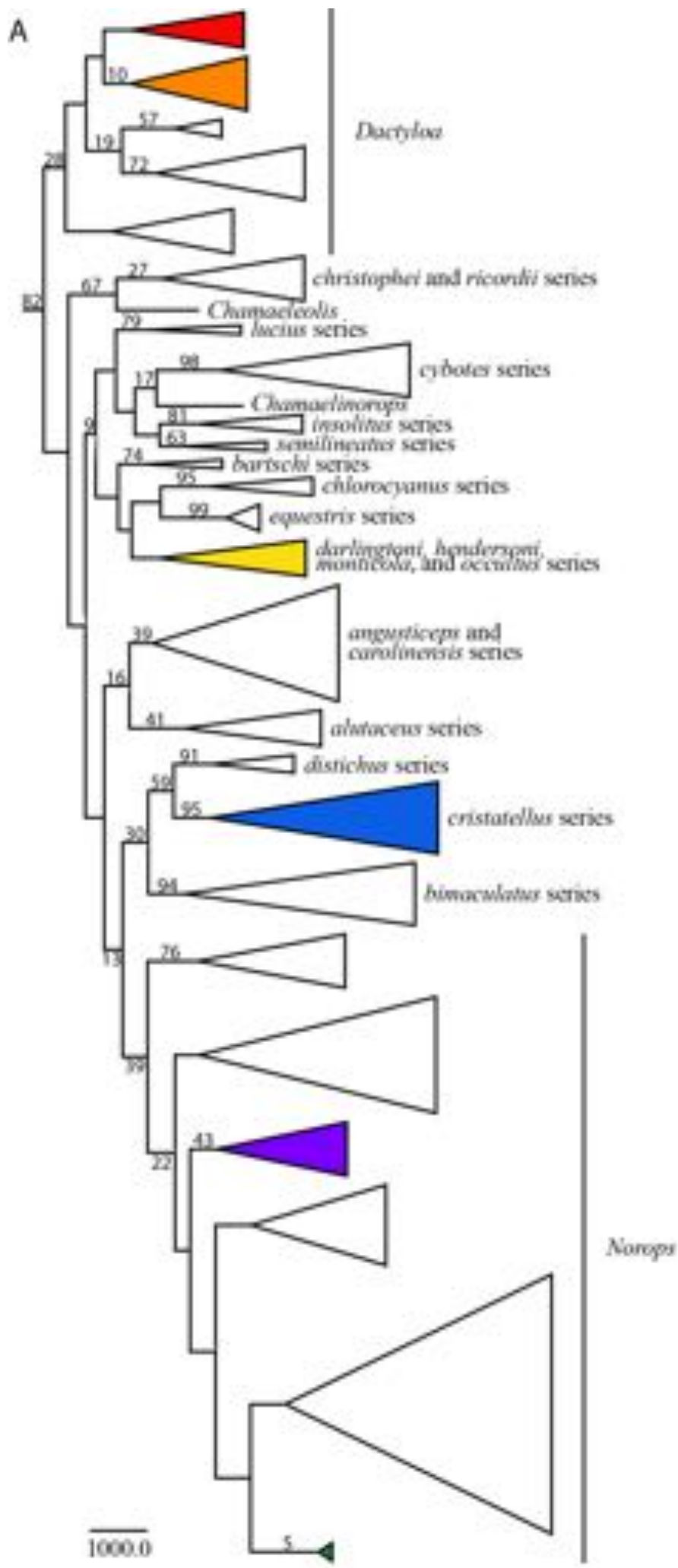

B

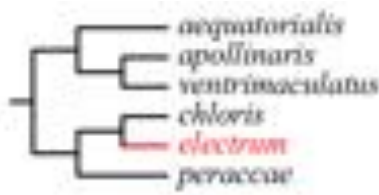

(1)

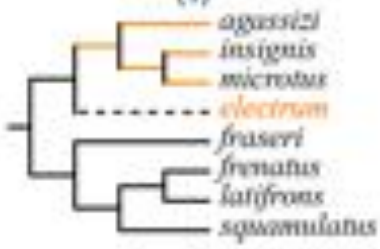

(5)

C

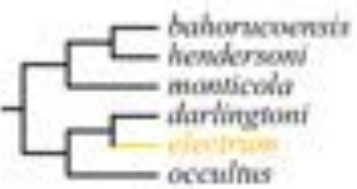

(1)

D

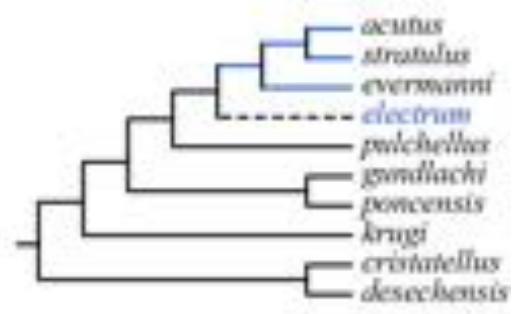

(5)

E

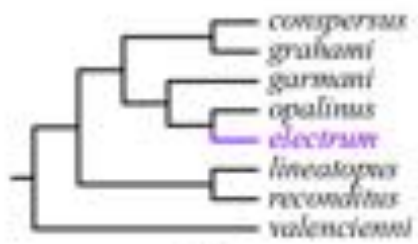

(1)

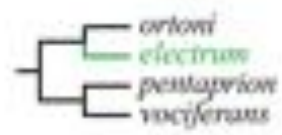

(1)

Figure 3. 